\title{
Leukemoid Reaction in a Severe COVID-19 Patient
}

Diogo R. Sene ${ }^{1}$, Diego M. Watashi ${ }^{2}$

1. Intensive Care Unit, Hospital Dr. Arnaldo Pezzuti, Mogi das Cruzes, BRA 2. Critical Care Medicine, Universidade de Mogi das Cruzes, Mogi das Cruzes, BRA

Corresponding author: Diego M. Watashi, diegowatashi17@gmail.com

\begin{abstract}
Leukemoid reaction is defined by a leukocyte level above $50 \times 10^{3} / \mu \mathrm{L}$ with a predominance of mature neutrophils and the presence of immature granulocytic forms in the peripheral blood (left shift). We report a case of a 36-year-old woman with severe coronavirus disease 2019 (COVID-19) infection admitted to the ICU with a leukocytosis of $70.9 \times 10^{3} / \mu \mathrm{L}$ white blood cells (WBC) throughout her hospitalization. A left shift with bandemia along with toxic granulations was also noticed and further investigation excluded more commonly known causes. A presumptive diagnosis of leukemoid reaction was made secondary to COVID-19 infection; however, it could not be confirmed since workup for lymphoproliferative disorders could not be performed as the patient passed away. The leukemoid reaction could be associated with severe COVID-19 infection; however, more data are needed to evaluate this association.
\end{abstract}

Categories: Internal Medicine, Infectious Disease, Hematology

Keywords: covid-19, leukocytosis, case report, leukemoid reaction, sars-cov-2

\section{Introduction}

Leukemoid reaction (LR) is defined by a leukocyte count above $50 \times 10^{3} / \mu \mathrm{L}$ with a predominance of mature neutrophils and the presence of immature granulocytic forms in the peripheral blood (left shift). It is caused by inflammatory reactions or organic stress with different etiologies: infections, drugs, intoxications, hemorrhage, and malignancy [1].

Since the first coronavirus disease 2019 (COVID-19) reports, the hematologic manifestations were described in most cases as normal or decreased leukocyte count and lymphopenia, and less commonly, leukocytosis. This case report describes a rare presentation of leukemoid reaction in a COVID-19 patient [2].

Review began 08/25/2021 Review ended 09/07/2021 Published 09/10/2021

\section{(๑) Copyright 2021}

Sene et al. This is an open access article distributed under the terms of the Creative Commons Attribution License CC-BY 4.0., which permits unrestricted use, distribution, and reproduction in any medium, provided the original author and source are credited.

\section{Case Presentation}

A 36-year-old woman presented to the emergency department reporting worsening shortness of breath associated with malaise and headaches. Four days prior, the patient tested positive for COVID-19 infection at a primary care facility and was prescribed azithromycin and prednisone for five days. On examination at the emergency department, she was in respiratory distress. Her vital signs were: temperature $37.9^{\circ} \mathrm{C}$, oxygen saturation $85 \%$ on room air, heart rate 112 /minute, and respiratory rate $31 /$ minute. There were no other positive findings on her physical examination. Her past medical history included obesity (BMI of $35.7 \mathrm{~kg} / \mathrm{m}^{2}$ ), diabetes, and hypertension for which she was non-compliant with the treatment.

Initial blood workup showed elevated inflammatory markers (C-reactive protein: $55.9 \mathrm{mg} / \mathrm{dl}$, erythrocyte sedimentation rate [ESR]: >100 mm/hr, ferritin: $3014 \mathrm{ng} / \mathrm{mL}$, and elevated D-Dimer: $1.94 \mathrm{mg}$ fibrinogen equivalent units [FEU]/L). Respiratory alkalosis was observed on arterial blood gas analysis and bilateral ground-glass infiltrates were noted on chest CT.

Despite being on oxygen support by face mask at $15 \mathrm{~L} / \mathrm{min}$, her symptoms rapidly worsened requiring intubation and mechanical ventilation. She was transferred to the medical intensive care unit (ICU) for proper care. During her stay in the ICU, the patient was started on dexamethasone $6 \mathrm{mg}$ per day for 10 days and prophylactic enoxaparin and was ventilated in accordance with the ARDSnet (Acute Respiratory Distress Syndrome Network) guide [3].

On the following days in the ICU, the patient's condition deteriorated showing prolonged capillary refill time and low blood pressure. Fluid resuscitation and further norepinephrine were initiated as well as empiric antibiotic therapy with meropenem was started. Routine infection workup including blood, respiratory, and urine cultures was requested.

Laboratory findings showed marked leukocytosis with left shift (white blood cells [WBC] $27.8 \times 10^{3} / \mu \mathrm{L}$ with absolute neutrophil count [ANC] $20.2 \times 10^{3} / \mu \mathrm{L}$ ), and normocytic anemia (hemoglobin of $9.4 \mathrm{gm} / \mathrm{dL}$, mean 
corpuscular volume $[\mathrm{MCV}] 82.9$, mean corpuscular hemoglobin $[\mathrm{MCH}] 27.3$ ) and lactate of $3 \mathrm{mmol} / \mathrm{L}$ were observed.

Subsequent laboratory investigations showed persistent leukocytosis with left shift (WBC $70.9 \times 10^{3} / \mu \mathrm{L}$ and ANC $\left.44.01 \times 10^{3} / \mu \mathrm{L}\right)$, metamyelocytes (9\%), myelocytes (6\%), mild lymphocytosis $\left(5.67 \times 10^{3} / \mu \mathrm{L}\right)$, monocytosis $\left(2.13 \times 10^{3} / \mu \mathrm{L}\right.$ ), and toxic granulations (Figure 1). Blood, tracheal aspirate, central venous catheter tip, and urine culture results were negative and the antibiotic therapy was stopped. A thorough physical exam showed no positive findings. Procalcitotin was lower than $0.1 \mathrm{ng} / \mathrm{mL}$, leukocytic alkaline phosphatase score was 170, uric acid level was $7.1 \mathrm{mg} / \mathrm{dL}$, vitamin B12 level was $183 \mathrm{pg} / \mathrm{mL}$, and folic acid level was $5.4 \mathrm{ng} / \mathrm{L}$. Moreover, there were no positive chest X-ray findings. Further workup for the lymphoproliferative disorder was not possible as the patient passed away in the hospital on day 14 .

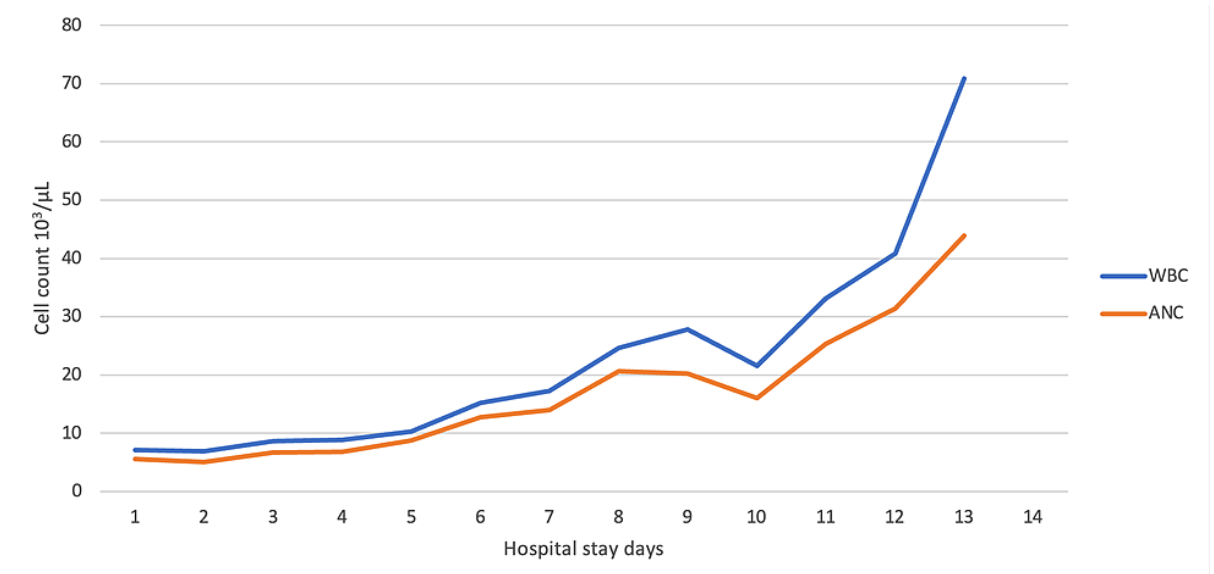

FIGURE 1: White blood cells and absolute neutrophil values during the hospital stay.

WBC, white blood cells; ANC, absolute neutrophil count.

\section{Discussion}

LR is caused by an inflammatory stimulus that originated from outside of the bone marrow. The most common causes are infections like Clostridium difficile, disseminated tuberculosis, and shigellosis. Other associated conditions are exposure to drugs (corticosteroids, minocycline, and recombinant hematopoietic growth factors), ethylene glycol intoxication, malignancy (carcinoma, melanoma, Hodgkin's lymphoma, and sarcoma), and hemorrhage $[1,4]$.

LR share close features with leukemia, requiring the exclusion of chronic myelogenous leukemia and chronic neutrophilic leukemia in all cases. Many tests may distinguish those etiologies, including white blood cells count with differential count, peripheral blood smear, leukocyte alkaline phosphatase (LAP) score, serum vitamin B12, bone marrow aspiration, cytogenetic studies, immunophenotyping of peripheral blood and bone marrow, serum levels of hematopoietic growth factors, and clonality studies of blood neutrophils. The diagnosis of $\mathrm{LR}$ is made by the presence of mature neutrophilia in the peripheral blood smear with a left shift without known underlying conditions and excluding leukemia $[4,5]$.

The presence of an LR should first raise concern for infection, especially in patients exposed to high infection risk procedures or housing, as an ICU. Therefore, a thorough investigation must be conducted to exclude this diagnosis.

Corticosteroids are a well-known cause of increasing WBC counts [6,7]. Increases in WBC counts of an average of $4 \times 10^{3} / \mu \mathrm{L}$ have been reported; however, it may vary, mostly related to the dose of glucocorticoid [8]. Moreover, glucocorticoid-induced leukocytosis is generally not associated with worsening in the condition that is being appropriately treated and the left shift is not as pronounced as it is in infection [9].

The treatment of LR should be guided by the underlying etiology, and a normalization of the leukocyte count is expected after the etiology resolution [5].

While a rare finding, few case reports show the presence of LR in patients with severe COVID-19. Similar case reports of LR with COVID-19 are presented in Table 1. 


\section{Cureus}

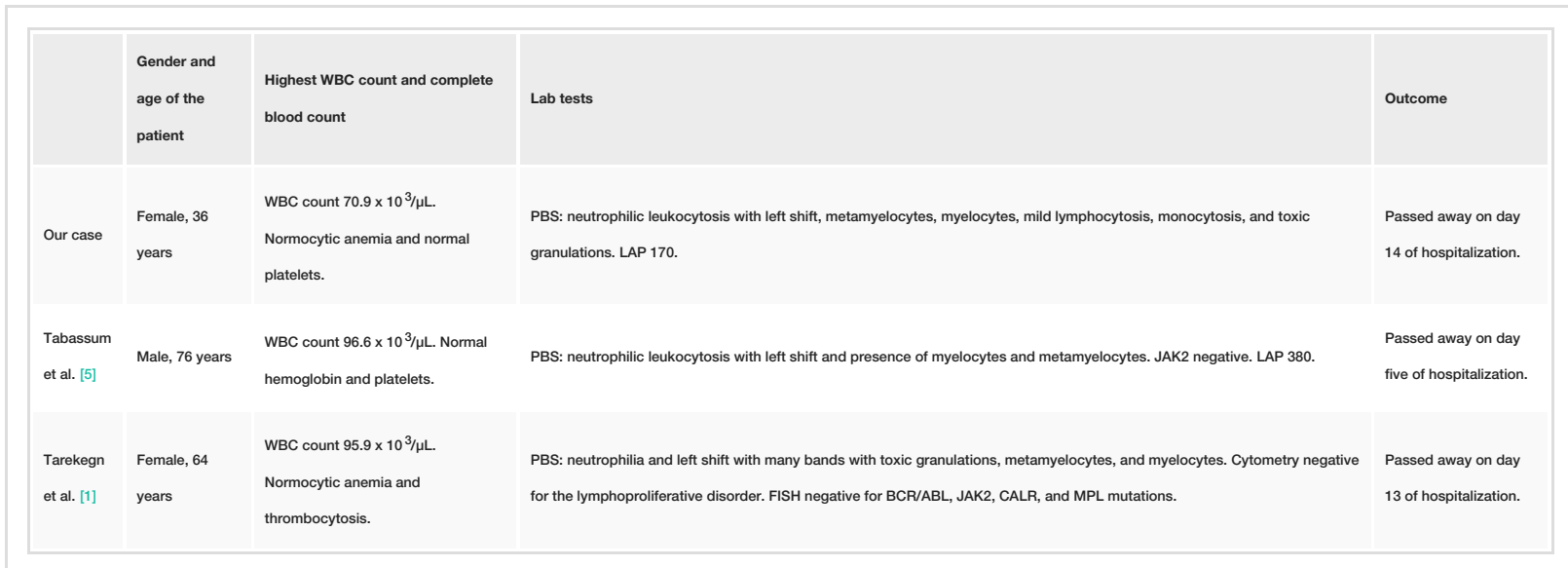

TABLE 1: Similar case reports of COVID-19 associated with leukemoid reactions.

WBC, white blood cell count; PBS, peripheral blood smear; LAP, leukocytic alkaline phosphatase; FISH, fluorescence in situ hybridization; JAK2, Janus kinase 2; CALR, calregulin gene; MPL, thrombopoietin receptor gene.

All reports describe a poor outcome, with the patients passing at different moments of the disease. LR has been reported to be a high mortality indicator in infectious etiologies [10]. Recent literature suggests a correlation between neutrophilia and disease severity in COVID-19 [11]. But the lack of data cannot confirm an association between LR in COVID-19 and disease severity or mortality. Workup for lymphoproliferative disorders was not performed due to the unfortunate death of this patient, creating uncertainty in the diagnosis of LR secondary to COVID-19.

\section{Conclusions}

The diagnosis of LR in a COVID-19 patient should be considered facing extremely high WBC levels. Other severe conditions should be excluded as an etiology of the LR. More data are needed to study any prognostic value of LR in COVID-19.

\section{Additional Information \\ Disclosures}

Human subjects: Consent was obtained or waived by all participants in this study. Conflicts of interest: In compliance with the ICMJE uniform disclosure form, all authors declare the following: Payment/services info: All authors have declared that no financial support was received from any organization for the submitted work. Financial relationships: All authors have declared that they have no financial relationships at present or within the previous three years with any organizations that might have an interest in the submitted work. Other relationships: All authors have declared that there are no other relationships or activities that could appear to have influenced the submitted work.

\section{References}

1. Tarekegn K, Colon Ramos A, Sequeira Gross HG, Yu M, Fulger I: Leukemoid reaction in a patient with severe COVID-19 infection. Cureus. 2021, 13:e13598. 10.7759/cureus.13598

2. Zhu J, Ji P, Pang J, et al.: Clinical characteristics of 3062 COVID-19 patients: a meta-analysis . J Med Virol. 2020, 92:1902-14. 10.1002/jmv.25884

3. NIH NHLBI ARDS clinical network mechanical ventilation protocol summary . (2014). Accessed: June 9, 2021: http://www.ardsnet.org/files/ventilator_protocol_2008-07.pdf.

4. Sakka V, Tsiodras S, Giamarellos-Bourboulis EJ, Giamarellou H: An update on the etiology and diagnostic evaluation of a leukemoid reaction. Eur J Intern Med. 2006, 17:394-8. 10.1016/j.ejim.2006.04.004

5. Tabassum SA, Bibi T, Tariq F, et al.: Unusal leukemoid reaction in a COVID-19 patient: a case report . Biol Clin Sci Res J. 2020, 2020:e034. 10.47264/bcsrj0101034

6. Abramson N, Melton B: Leukocytosis: basic of clinical assessment . Am Fam Physician. 2000, 62:2053-60

7. Nakagawa M, Terashima T, D'yachkova Y, Bondy GP, Hogg JC, van Eeden SF: Glucocorticoid-induced granulocytosis: contribution of marrow release and demargination of intravascular granulocytes. Circulation. 1998, 98:2307-13. 10.1161/01.cir.98.21.2307

8. Dale DC, Fauci AS, Guerry D IV, Wolff SM: Comparison of agents producing a neutrophilic leukocytosis in man. Hydrocortisone, prednisone, endotoxin, and etiocholanolone. J Clin Invest. 1975, 56:808-13. 10.1172/TCI108159

9. Shoenfeld Y, Gurewich Y, Gallant LA, Pinkhas J: Prednisone-induced leukocytosis. Influenced of dosage, method and duration of administration on the degree of leukocytosis. Am J Med. 1981, 71:773-8. 10.1016/0002-9343(81)90363-6 


\section{Cureus}

10. Portich JP, Faulhaber GA: Leukemoid reaction: a 21st-century cohort study. Int J Lab Hematol. 2020, 42:1349. 10.1111/ijlh.13127

11. Huang G, Kovalic AJ, Graber CJ: Prognostic value of leukocytosis and lymphopenia for coronavirus disease severity. Emerg Infect Dis. 2020, 26:1839-41. 10.3201/eid2608.201160 